\title{
Screening for mental illness in general population and primary care settings
}

\author{
KATHRYN M. MAGRUDER
}

Over approximately the last $20-30$ years, there has been a great deal of research devoted to the development of reliable, valid screening instruments for detecting mental illness. These efforts have resulted in a number of excellent screeners that can be used in clinical practice, public health practice, and research. Examples include, the Zung Self-rating Depression Scale (SDS) (Zung, 1965), the Beck Depression Inventory (BDI) (Beck et al., 1961), the Center for Epidemiologic Studies Depression scale (CES-D) (Radloff, 1977), the General Health Questionnaire (GHQ) (Goldberg, 1972), the Geriatric Depression Scale (GDS) (Yesavage et al., 1983), the Michigan Alcoholism Screening Test (MAST) (Seltzer, 1971), the Veterans Alcoholism Screening Test (VAST) (Magruder-Habib et al., 1982), and the CAGE questions for alcoholism (Ewing, 1984) just to mention a few. In addition, the increased recognition in recent years of the importance of primary care practitioners in detection, treatment, and referral of patients with mental illness has highlighted the needs of non-mental health providers for quickly obtainable information that covers multiple mental health problems and moves beyond screening. This has led to the recent development of the PRIME-MD and the SDDS-PC - two screening and diagnostic instruments which are designed specifically for use in primary care (Spitzer et al., 1994; Broadhead et al., 1995). Clearly, there is a plethora of screening instruments with excellent performance characteristics. What is lacking, though, is data on the utility of these instruments in practice. Are they useful in public health practice? in clinical practice? How effective are screening programs for mental illness?

There are several different types of screening pro-

Indirizzo per la corrispondenza: Dr. K.M. Magruder, National Institute of Mental Health, Parklawn Building Room 10-105, Rockville, Maryland 20857, USA.

Fax $+1-301-443.4045$. grams which serve very different purposes and should be noted here. First, there is classic screening, in which whole populations or subpopulations at risk are screened. Screening all new recruits for military service, all hospital admissions, all pregnant women presenting for care, or all patients coming for a periodic health examination are examples of classic screening programs. A second situation, case finding, still uses screening instruments, but individuals are selected (nonrandomly) by their physicians because of a particular risk profile. Selective screening by sigmoidoscopy of patients with a history of inflammatory bowel disease, adenomatous polyps, or a family history of colorectal cancer would be an example of case finding. A third scenario is what we have called "voluntary» screening (Magruder et al., 1995). In this situation, screening is offered and individuals select themselves to be screened, resulting in a nonrandom group with unique clinical and sociodemographic characteristics. Although akin to case finding in its nonrandomness, voluntary screening is slightly different in that it is patient or client initiated, whereas case finding is clinician initiated. Examples of voluntary screening include screening in shopping malls or pharmacies and special programs, such as National Depression Screening Day and National Anxiety Disorders Screening Day in the United States.

With all the attention to mental health screening instruments and promotion of mental health screening opportunities, it is worth asking the question: Does screening make a difference? Aside from research uses, are there measurable changes in outcomes which can be attributable to screening? Is the prevalence of mental disorder lower in screened populations? Is there a higher rate of treatment? Is treatment occurring at earlier stages? In order to be effective, a screening program should detect the illness or condition at an earlier stage than without screening, leading to earlier intervention and result- 


\section{K. M. Magruder}

ing in a better prognosis. Among the several types of screening programs, the evidence for effectiveness varies considerably.

In the case of classic screening, there has never been any research project to demonstrate that populations which have systematically been screened for mental illness fare any better than similar populations which have not been screened. This has not been shown in either the primary care setting or the general population, despite the intuitive appeal that there should be better outcomes as a result of earlier intervention (due to screening). The lack of data in this area is the main reason that the United States Preventive Services Task Force (1989) does not recommend routine screening for depression (or any other mental illness or substance abuse disorder. Needed are studies comparing screened to unscreened populations in terms of prevalence, morbidity, and mortality related to the target condition. Studies could be similar to those conducted on breast cancer which demonstrate that screening by mammography reduces breast cancer mortality (e.g. Tabar et al., 1985; Andersson et al., 1988; Verbeek et al., 1984), and those on hypertension which demonstrate that blood pressure screening reduces the incidence of hypertension related events and mortality (e.g. Hansson, 1988; Hypertension Detection and Follow-Up Program Cooperative Group, 1979).

Data with regard to use of screening instruments for case finding (i.e., for those at increased risk for depression) are similarly nonexistent. It is interesting that the United States Preventive Services Task Force does recommend maintaining uan especially high index of suspension for depressive symptoms in those persons at increased risk for depression»" and that «depressed persons identified through screening receive adequate follow-up care.» It is likely that instruments such as the PRIME-MD and the SDDS-PC (despite their length) may prove to be useful case finding tools since they can be used selectively and also render a diagnosis.

Interesting and provocative are the data that are being generated from voluntary screening programs such as the US National Depression Screening Day - a voluntary screening program where individuals interested in being screened for depression have the opportunity to take a depression screening test anonymously, discuss the results with a mental health professional, and (if indicated) be referred for further evaluation and treatment (Jacobs, 1991). The data indicate that $76.6 \%$ of individuals who come for screening have at least minimal depressive symptoms, $53.3 \%$ at least moderate, and $22.6 \%$ severe symptoms (Magruder et al., 1995). Few of those who score positive for depression are currently in treatment. Positive predictive values are between $88.7 \%$ and $95.5 \%$ depending on the cut-off score used. Furthermore, follow-up data show that $56.5 \%$ of those who receive a recommendation to go for further evaluation do so, with the great majority $(77.6 \%$ ) continuing in treatment (Greenfield et al., 1996). The best predictors of who complies with follow-up recommendations are severity of depression (the more severely depressed are more compliant) and prior treatment history (those who have previously been treated are more apt to go to follow-up). Similar results have been reported from the National Anxiety Disorders Screening Day (Guardino, 1996; Struening et al., 1996; Peselow et al., 1996). Although incomplete because there are no data on symptomatic and functional improvement, the results so far are encouraging that voluntary screening can be an effective means of getting untreated depressed individuals into appropriate treatment.

Regardless of which screening approach is taken, which screener is used, or what the psychometric properties of the instrument are, there are some fundamental issues that make screening for mental illness different from screening for other medical illnesses. Even though these issues increase the level of complexity involved in screening for mental illness, it is possible to attend to them in developing a screening program.

First, screening is an activity to detect illnesses and conditions at a stage where the individual is not aware of his illness or condition, for example, hypertension or breast cancer. With earlier detection, earlier intervention is possible, resulting in improved outcome. Thus, programs such as screening for breast cancer or hypertension enable asymptomatic individuals to come to treatment earlier and improve their prognosis. With mental illness, however, because the nature of diagnosis is in evaluating symptoms as reported by the patient, it is not possible to say that the purpose of screening is to detect mental disorder in asymptomatic individuals. But it is possible to say that screening can help an individual or a provider to consolidate and interpret a set of symptoms to form a probable diagnosis - still resulting in earlier entry into treatment.

The second major issue that makes screening for mental illness somewhat unique is the stigma that is still attached to having a mental illness. Thus, con- 
fidentiality of results, and in some cases the assurance of anonymity, are important if screening is to be acceptable to target groups. Even so, stigma may cause many to refuse or avoid screening for a mental illness. In some mental disorders (e.g., alcoholism, eating disorder), the denial that is such an integral part of the disorder may keep some of those in need of treatment away from screening opportunities.

Third, individuals may be at very different stages of readiness to initiate treatment for their mental health problems, and screening programs may be differentially effective, depending on the stage of readiness. Research has shown that there are five predictable stages that individuals move through as they change from unhealthy to healthy behaviors or lifestyles (Prochaska et al., 1992). Individuals start at the precontemplation stage, in which they may not even be aware that they have a problem (and certainly have no intention to change behavior in the foreseeable future) and move through the contemplation, preparation, action, and maintenance stages. Furthermore, depending on their stage of readiness to change, individuals respond differentially to interventions. Thus, offering treatment for depression to a primary care patient who is in the precontemplation stage is not apt to be as acceptable as to a patient who is in the contemplation, preparation, or action stage. Because classic screening identifies people regardless of their stage of readiness, it is likely that only those who are in the preparation or action stages will move on to treatment. In contrast, because individuals themselves take the initiative in voluntary screening - and are thus likely to be in the preparation or action stage - it follows that they will be more apt to follow through with treatment recommendations based on screening results. Case finding is probably somewhere in between classic and voluntary screening, because the clinician has the opportunity to discuss the reason for taking the screening test and move the patient to a further stage of readiness to accept treatment.

Public ignorance and misconception about mental disorders have no doubt kept many people who could benefit from treatment at very low levels of readiness to change. Thus, a fourth issue which must be addressed in order for screening programs to succeed is the level of understanding by the public about mental disorders. Public education programs, such as the US Depression Awareness, Recognition, and Treatment (or D/ART) campaign and the British Defeat Depression campaign, can be tremen- dously helpful in this regard. Although it is difficult to evaluate statistically the success of these programs, it is likely that they provide the underpinnings for moving people along the stages of readiness to change, making it possible for people in need of treatment to take advantage of screening opportunities which enable them to take the first step toward accessing help.

A fifth issue relates to the availability of effective care - both in the specialty mental health sector and the general medical sector. If clinicians are not prepared to deal effectively with those who present for treatment as a result of screening, then screening programs (regardless of which type) will fail. General practitioners especially need training to deal with certain mental disorders (e.g., depression, anxiety). Physician education programs which run concurrently with voluntary or classic screening can help to boost their ultimate effectiveness.

In summary, it is an opportune time for mental health professionals with an interest in epidemiology and public health to implement screening programs which have a real chance to make a measurable impact on public mental health. Clearly, more research is needed in certain areas, particularly in the area of early intervention altering the natural course of disorder. Despite this, there is a great deal of experience and information around voluntary screening programs which have been offered in the United States, and which may prove to be transportable internationally. There are now plans to develop additional screening days for alcohol and eating disorders. In addition, computerized telephone screenings (Baer et al., 1995) are being offered at work sites, academic sites, and primary care settings. If evaluation of these new programs is as encouraging as results from National Depression Screening Day\}, then voluntary screening for mental disorders may prove to be an effective means of reaching those in need of treatment.

\section{REFERENCES}

Andersson I., Aspegren K., Janzon L., Landberg T., Lindholm K., Linell F., Ljungberg O., Ranstam J. \& Sigfusson B. (1988). Mammographic screening and mortality from breast cancer: the Malmo Mammographic Screening Trial. British Medical Journal 297, 943-948.

Baer L., Jacobs D.G., Cukor P., O Laughlen J., Coyle J.T. \& Magruder K.M. (1995). Automated telephone screening survey for

Epidemiologia e Psichiatria Sociale, 5, 3, 1996 
depression. Journal of the American Medical Association 273, 1943-1944.

Beck A.T., Ward C.H., Mendelson M., Mock J. \& Erbaugh J. (1961). An inventory for measuring depression. Archives of General Psychiatry 4, 561-571.

Broadhead W.E., Leon A., Weissman M., Barrett J.E., Blacklow R.S., Gilbert T.T., Keller M.B., Olfson M. \& Higgins E.S. (1995). Development and validation of the SDDS-PC screen for multiple mental disorders in primary care. Archives of $\mathrm{Fa}$ mily Medicine 4, 211-219.

Ewing J.A. (1984). Detecting alcoholism, the CAGE questionnaire. Journal of the American Medical Association 252, 19051907.

Goldberg D.P. (1972). The Detection of Psychiatric Illness by Questionnaire. Oxford University Press: London.

Greenfield S.F., Jacobs D.G., Reizes J.M., Muenz L. \& Kopans B. (1996). Screening effectiveness: the National Depression Screening Day telephone follow-up survey. Paper presented at the 1996 Annual Meeting of the American Psychiatric Association, New York.

Guardino M. (1996). The rationale for National Anxiety Screening Day. Paper presented at the 1996 Annual Meeting of the American Psychiatric Association, New York.

Hansson L. (1988). Current and future strategies in the treatment of hypertension. American Journal of Cardiology 61, 2C-7C.

Hypertension Detection and Follow-up Program Cooperative Group (1979). Five-year findings of the Hypertension Detection and Follow-Up Program. I. Reduction in mortality of persons with high blood pressure, including mild hypertension. Journal of the American Medical Association 242, 2562-2572.

Jacobs D.G. (1991). Depression Screening Procedure Manual. McLean Hospital: Belmont, Mass.

Magruder K.M., Norquist G.S., Feil M.B., Kopans B. \& Jacobs D. (1995). Who comes to a voluntary depression screening program? American Journal of Psychiatry 152, 1615-1622.

Magruder-Habib K.M., Harris K.E. \& Fraker G.G. (1982). Validation of the Veterans Alcoholism Screening Test. Journal of Studies on Alcohol 43, 910-926.

Peselow E.D., Struening E., Pitman J. \& Welkowitz L. (1996). Follow-up for patients who attended National Anxiety Screening
Day. Paper presented at the 1996 Annual Meeting of the American Psychiatric Association, New York.

Prochaska J.O., Di Clemente C.C. \& Norcross J.C. (1992). In search of how people change: applications to addictive behaviors. American Psychologist 47, 1102-1114.

Radloff L.S. (1977). The CES-D scale: A self report depression scale for research in the general population. Applied Psychological Measurement 1, 385-401.

Seltzer M.L. (1971). Michigan Alcoholism Screening Test: the quest for a new diagnostic instrument. American Journal of Psychiatry 129, 342-345.

Spitzer R., Williams J., Kroenke K. et al. (1994). Utility of a new procedure for diagnosing mental disorders in primary care: The PRIME-MD 1000 study. Journal of the American Medical Association 272, 1749-1755.

Struening E., Guardino M.T., Pitman J. \& Welkowitz L. (1996). The results of National Anxiety Screening Day. Paper presented at the 1996 Annual Meeting of the American Psychiatric Association, New York.

Tabar L., Fagerberg C.J.G., Gad A., Baldetorp L., Holmberg L.H., Grontoft O., Ljungquist U., Lundstrom B., Manson J.C., Eklund G. et al. (1985). Reduction in mortality from breast cancer after mass screening with mammography: randomised trial from the Breast Cancer Screening Working Group of the Swedish National Board of Health and Welfare. Lancet 1, 829-832.

United States Preventive Services Task Force (1989). Guide to Clinical Preventive Services: An Assessment of the Effectiveness of 169 Interventions. Williams and Wilkins: Baltimore.

Verbeek A.L.M., Hendricks J.H.C.L., Hollan P.R. et al. (1984). Reduction of breast cancer mortality through mass screening with modern mammography: first results of the Nijmegen Project, 1975-1981. Lancet 1, 1222-1224.

Yesavage J.A., Rose T.L., Lum O., Huang V., Adey M. \& Leirer V.O. (1983). Development and validation of a geriatric depression screening scale: A preliminary report. Journal of Psychosomatic Research 17, 37-49.

Zung W.W.K. (1965). A self-rating depression scale. Archives of General Psychiatry 12, 63-70. 